\title{
Association and mechanism of garlic consumption with gastrointestinal cancer risk: A systematic review and meta-analysis
}

\author{
YANGYANG WANG $^{1-3}$, PING HUANG ${ }^{2}$, YUFEI WU ${ }^{1-3}$, DUANRUI LIU ${ }^{1,3}$, \\ MINGYU JI ${ }^{2}$, HUANJIE LI $^{1,2}$ and YUNSHAN WANG ${ }^{1-3}$ \\ ${ }^{1}$ School of Medicine, Cheeloo College of Medicine, Shandong University, Jinan, Shandong 250012; \\ ${ }^{2}$ Medical Research and Laboratory Diagnostic Center; ${ }^{3}$ Basic Medical Research Center, \\ Jinan Central Hospital Affiliated to Shandong First Medical University, Jinan, Shandong 250013, P.R. China
}

Received December 9, 2021; Accepted February 2, 2022

DOI: $10.3892 / \mathrm{ol} .2022 .13245$

\begin{abstract}
Gastrointestinal cancer is one of the most commonly diagnosed cancer type worldwide, with millions of cases per year. The aim of this review was to investigate the relationship between garlic intake and the risk reduction of gastrointestinal cancer. We performed saturated data mining on various public domain databases, including PubMed (https://pubmed.ncbi.nlm.nih.gov/), Embase (https://www. embase.com/landing?status=grey), and Cochrane Library (https://www.cochranelibrary.com/), with key terms including: 'garlic', 'allium', 'stomach', 'gastric', 'colon', 'neoplasms', 'cancer' and 'tumor'. Furthermore, we identified additional references through expert manual curation. Finally, a meta-analysis was conducted to determine whether garlic intake reduces the risk of gastric and/or colorectal cancer. The association between garlic intake and reduction in the risk of gastric cancer [odds ratio $(\mathrm{OR})=0.65,95 \%$ confidence interval $(C I)=0.49-0.87, P<0.001]$ were clear. Nine studies on garlic intake and colorectal cancer showed that garlic reduced cancer risk with a statistical significance $(\mathrm{OR}=0.75,95 \% \mathrm{CI}=0.65-0.87$, $\mathrm{P}<0.001)$. We summarized that four main organic sulfides in garlic, diallyl disulfide (DADS), diallyl trisulfide (DATS), S-allylmercaptocysteine (SAMC) and allicin, may contribute to the regulation of tumor cell apoptosis, migration and the cell cycle. We identified the association between garlic intake and reduced risk of gastric and colorectal cancers and hypothesized that the active ingredients in garlic may act on multiple pathways to reduce the risk of gastrointestinal tumors according to published papers. Importantly, the potential tumor-preventing effect of these garlic ingredients warrants
\end{abstract}

Correspondence to: Dr Huanjie Li or Professor Yunshan Wang, School of Medicine, Cheeloo College of Medicine, Shandong University, 44 Wenhua Xi Road, Jinan, Shandong 250012, P.R. China E-mail: lihuanjie@sdu.edu.cn

E-mail: sdjnwys@163.com

Key words: gastrointestinal cancer, garlic, gastric cancer, meta-analysis further investigation in regards to the specific mechanism of the underlying antitumor activities.

\section{Introduction}

Gastrointestinal cancer is a health issue with worldwide concern, of which gastric and colorectal cancers are the most common types $(1,2)$. Despite the declining incidence and mortality, gastric cancer remains the third leading cause of cancer-related mortality in the world $(1,3)$. Nearly one million gastric cancer cases are diagnosed worldwide yearly, about half of which are found in the Chinese population (3). The incidence of colorectal cancer ranks third in the world, with highest morbidity and mortality in Asian populations (4). This distribution may be related to particular diet habits, increased level of stress and/or the Helicobacter pylori (H. pylori) infection prevalence in the Asian population $(5,6)$. China and South Korea prefer high-salt foods such as pickles and kimchi. Koreans consume more than twice the daily salt intake recommended by the World Health Organization $(7,8)$, and a high-salt diet can lead to a series of gastrointestinal diseases. Approximately half of the world's population is infected with $H$. pylori, while more than $55 \%$ are found in China $(9,10)$. Some studies have shown the relationship among vegetable consumption, gastrointestinal tumors and $H$. pylori (11-14), confirming that the increased consumption of fibers that are abundant in fresh fruits and vegetables is correlated with a reduced risk of gastrointestinal cancer (11).

Historically, garlic consumption has been associated with medicinal properties in ancient cultures of Indochina, the Mediterranean and Northern Africa (15). Garlic was shown to be able to reduce the risk of carcinogenesis in breast cancer, pancreatic cancer and esophageal cancer models (16-18). The S-allyl cysteine, diallyl disulfide, and other compounds found in garlic were suggested to have anticancer effects in cellular models $(15,19,20)$. Many potential anticancer mechanisms of these compounds were proposed, including the inhibition of cell proliferation, changes in enzyme activity and immune regulation $(21,22)$. The active ingredients in garlic oil correspond mainly to a family of organosulfur molecules, which selectively increase redox stress in cancer cells, leading to apoptosis and death (23). 
Previous meta-analyses and reviews exploring the relationship between garlic consumption and the risk of gastric and colorectal cancers have come to inconsistent conclusion (4,14,24-30). While some studies have found that garlic intake could reduce the risk of gastric and colorectal cancers $(14,30)$, others have shown that this effect may be overestimated (28). In a recent study by Li et al (13) with a follow-up of 22.3 years, garlic supplementation was found to be associated with reduced gastric cancer mortality $(\mathrm{OR}=0.81$, 95\% $\mathrm{CI}=0.57-1.13$ ), with a delayed effect on gastric cancer mortality. Although this finding provides a potential opportunity for the prevention of gastric cancer, further large-scale intervention trials are needed to confirm the effect. Based on the prospective data from the Nurses' Health Study involving 121,700 nurses [relative risk $(\mathrm{RR})=1.21,95 \% \mathrm{CI}=0.94-1.57$ ] and the Health Professionals Follow-up Study $(R R=1.00$, 95\% CI=0.71-1.42) involving 512,529 male health professionals, Meng et al (31) found no association between garlic consumption and the risk of colorectal cancer. However, this study was excluded in this research due to the lack of OR or RR data. Different diets in various populations, various levels of garlic consumption, and diverse patterns of garlic intake may cause inconsistent results from the different studies. Therefore, the effect of garlic on gastrointestinal cancer needs to be further confirmed. We conducted this meta-analysis to update the epidemiological evidence for the association between garlic and gastrointestinal cancer.

\section{Materials and methods}

Search strategy. This systemic review and meta-analysis is reported in accordance with the Preferred Reporting Items for Systematic Reviews and Meta-Analyses (PRISMA) statement. The study was registered in PROSPERO (CRD42020179464). The authors completed the data search in September 2021. All relevant studies that related to garlic intake for gastric and colorectal cancers from 1980 to 2021 were identified by searching in the following databases: Pubmed (https://pubmed.ncbi.nlm.nih.gov/), Embase (https://www. embase.com/landing?status=grey) and Cochrane Library (https://www.cochranelibrary.com/), with key terms including: 'garlic', 'allium', 'stomach', 'gastric', 'colon', 'neoplasms', 'cancer' and 'tumor'. The detailed searching strategies in each database are shown in Tables SI-SIII. All studies that met the requirements were reviewed. In addition, we expanded the search fields by including the references of the screened articles.

Study selection. During the database compilation, two investigators (YaW and DL) reviewed the full text of all the screened publications to determine whether the studies met the selection criteria. Further refinement of the database was completed by a third investigator (YuW). Studies were selected according to the following criteria: i) randomized controlled trials, case-control trials, or with cohort design; ii) studies that include the evaluation of the association between garlic intake and gastric or colorectal cancers over nearly 30 years; iii) studies that provide odds ratio (OR) or relative risk (RR) and with $95 \%$ confidence interval (CI) or providing sufficient information for OR/RR and 95\% CI calculation; iv) studies published within the last 30 years. The exclusion criteria included: i) reviews or meta-analyses; ii) non-English literature; iii) studies that lacked OR or RR data, or without sufficient data estimation results; iv) studies for which animal, cell, in vitro, and in vivo experiments were excluded. Since the majority of related studies were published in English, we chose not to include non-English studies which were very few and had lack of representativeness. The studies that were included were all non-truncated ones.

Data extraction. Data mining was performed by two investigators. Disagreements were resolved by consultation with a third investigator. The following information was extracted: author, year of publication, study period, study type, country, number of subjects, risk estimates and their $95 \% \mathrm{CI}$, description of garlic intake categories, and adjusted variables.

Risk of bias assessment. For randomized controlled trials (RCTs), we assessed the risk of bias using the Cochrane Risk of Bias assessment tool (32). The following characteristics were evaluated: random sequence generation, allocation concealment, blinding of participants and personnel, blinding of outcome assessment, incomplete outcome data, selective reporting and other biases. According to the recommendations of the Cochrane Handbook, a judgment to risk of bias was determined as three categories, including low risk, unclear risk and high risk. We used the Newcastle-Ottawa Scale (NOS) to assess the risk of bias in nonrandomized studies and scored the studies in three categories: selection (four questions), comparability of study groups (two questions), and ascertainment of exposure or outcome (three questions). Regarding the comparability, the study groups were awarded a maximum of two points; all the other questions were assigned a score of one point (33).

Statistical analysis. We first collected the OR of gastric cancer in various studies. Since the incidences of gastric cancer and colorectal cancer are relatively low, the approximate OR was obtained based on the RR. Then we explored the sources of heterogeneity and conducted a subgroup analysis by garlic intake level, geographic area, and the type of study.

The heterogeneity was assessed using the Cochrane's Q test and $\mathrm{I}^{2}$ statistic. P-values $<0.1$ and $\mathrm{I}^{2}$ values $>50 \%$ suggested the existence of heterogeneity. If significant heterogeneity existed, a random effect model was selected; otherwise, the fixed-effects model was used. Meanwhile, $\mathrm{I}^{2}$ values of $<30 \%, 30-60 \%$, and $>60 \%$ were considered to indicate low, moderate, and high heterogeneity, respectively. Results were assessed using forest plots. All data analysis was performed by STATA 12.0 (https://www.stata.com/).

Sensitivity analysis and subgroup analysis. Sensitivity analysis was performed to identify potential sources of heterogeneity according to garlic consumption level, research type and geographical area. Subgroup analysis was conducted to identify the cause of heterogeneity. Random effect model and fixed effect model were selected according to different degrees of heterogeneity.

Publication bias. Publication bias was assessed by conducting Begg's and Egger's funnel plot asymmetry tests, a P-value $<0.1$ suggested publication bias with statistical significance. 


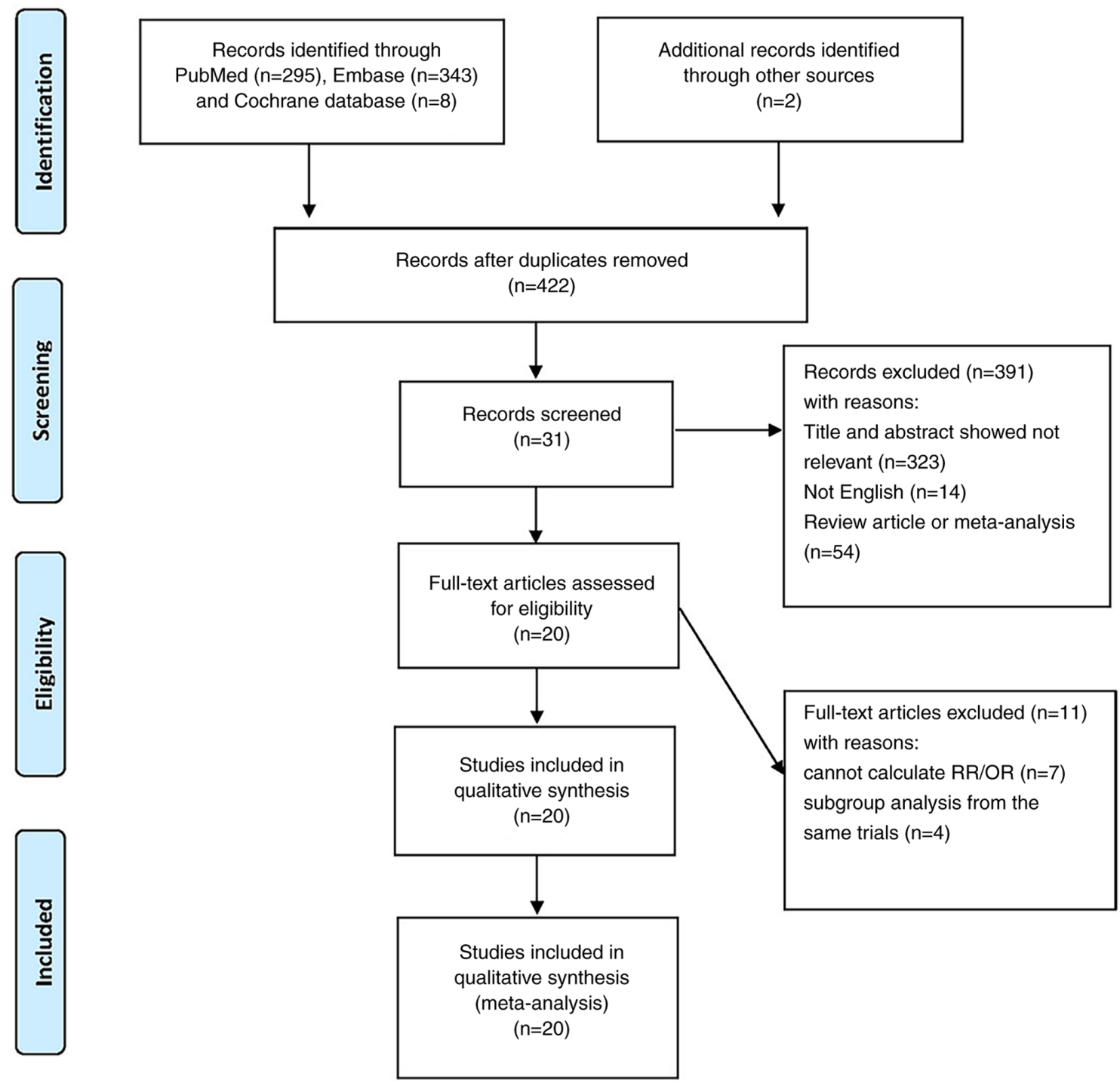

Figure 1. Flow diagram of the included studies. A total of 648 articles were initially searched, of which 226 articles were excluded as duplicate studies. Then we reviewed the titles and abstracts of each literature according to inclusion and exclusion criteria. We excluded additional articles, among which 323 were irrelevant to this study, 54 were meta-analyses and reviews, and 14 were non-English literature. After a careful review of the full texts in the remaining 31 articles, we finally included 20 articles after excluding 4 articles from the same study and 7 articles with insufficient data. OR, odds ratio; RR, relative risk.

\section{Results}

Study selection and characteristics. A total of 648 articles were initially identified, of which 226 articles were excluded as duplicate studies. Then we reviewed the titles and abstracts of each literature study according to inclusion and exclusion criteria. We excluded additional articles, among which 323 were irrelevant to this study, 54 were meta-analyses and review, and 14 were non-English literature. After a careful review of full texts in the remaining 31 articles, we finally included 20 articles after excluding 4 articles from the same study and 7 articles with insufficient data $(12,13,18,34-50)$. The flow of the literature search is documented in Fig. 1.

Of the 20 included articles (Table I), 11 were about garlic and gastric cancer, and 9 were about garlic and colorectal cancer. The 11 studies on garlic and gastric cancer were published between 1989 and 2020, including 3,299 patients with gastric cancer and 133,801 controls from one randomized controlled trial (13), 8 case-control studies $(18,34,35,37,38,40,41,47)$ and two cohort studies $(36,39)$. The study by Setiawan et al (35) was a large population-based case-control study of Shanghai and Qingdao, thus we divided this study into $a$ and $b$ to represent the results of Shanghai and Qingdao, respectively. The study by Kim et al (39) was composed of The Nurses' Health Study (NHS) and The Health Professionals Follow-up Study (HPFS); therefore, we split the results into two parts. The 9 studies on garlic and colorectal cancer include 7 case-control studies $(12,43,44,46,48-50)$ and two cohort studies $(42,45)$, published between 1994 and 2018 involving 8,519 colorectal cancer patients and 52,423 controls. Of the 9 studies, 4 were conducted in Europe, 2 in Asia, 2 in the US and 1 in Australia. Both Franceschi et al (46) and Dorant et al (42) studies included colon and rectal cancer, thus we believe that it was reasonable to separate colon and rectal cancers.

Overall and subgroup analysis of evidence. We conducted an overall estimation by categories of garlic consumption (Fig. 2). The ORs of all the studies were extracted for the 


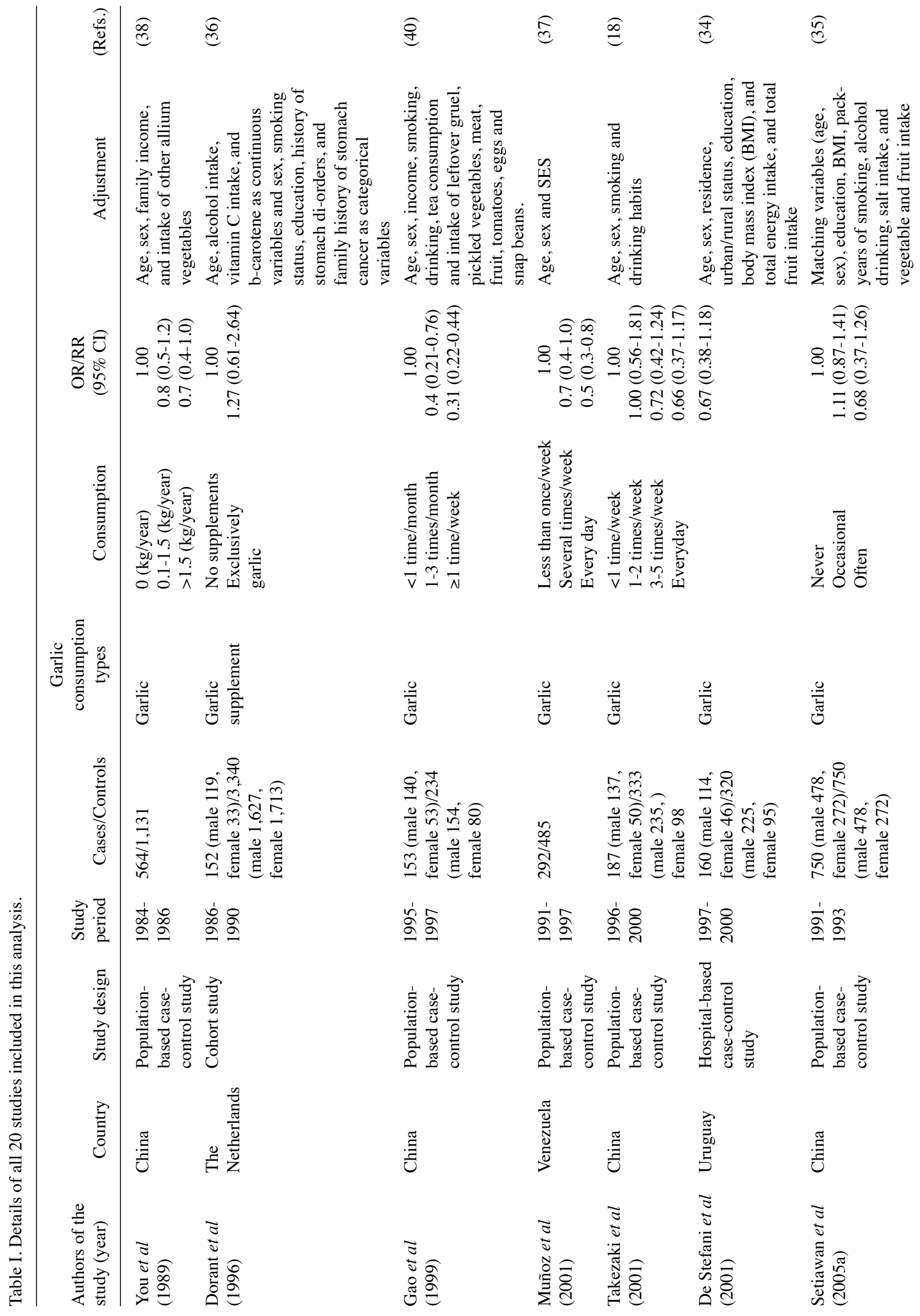




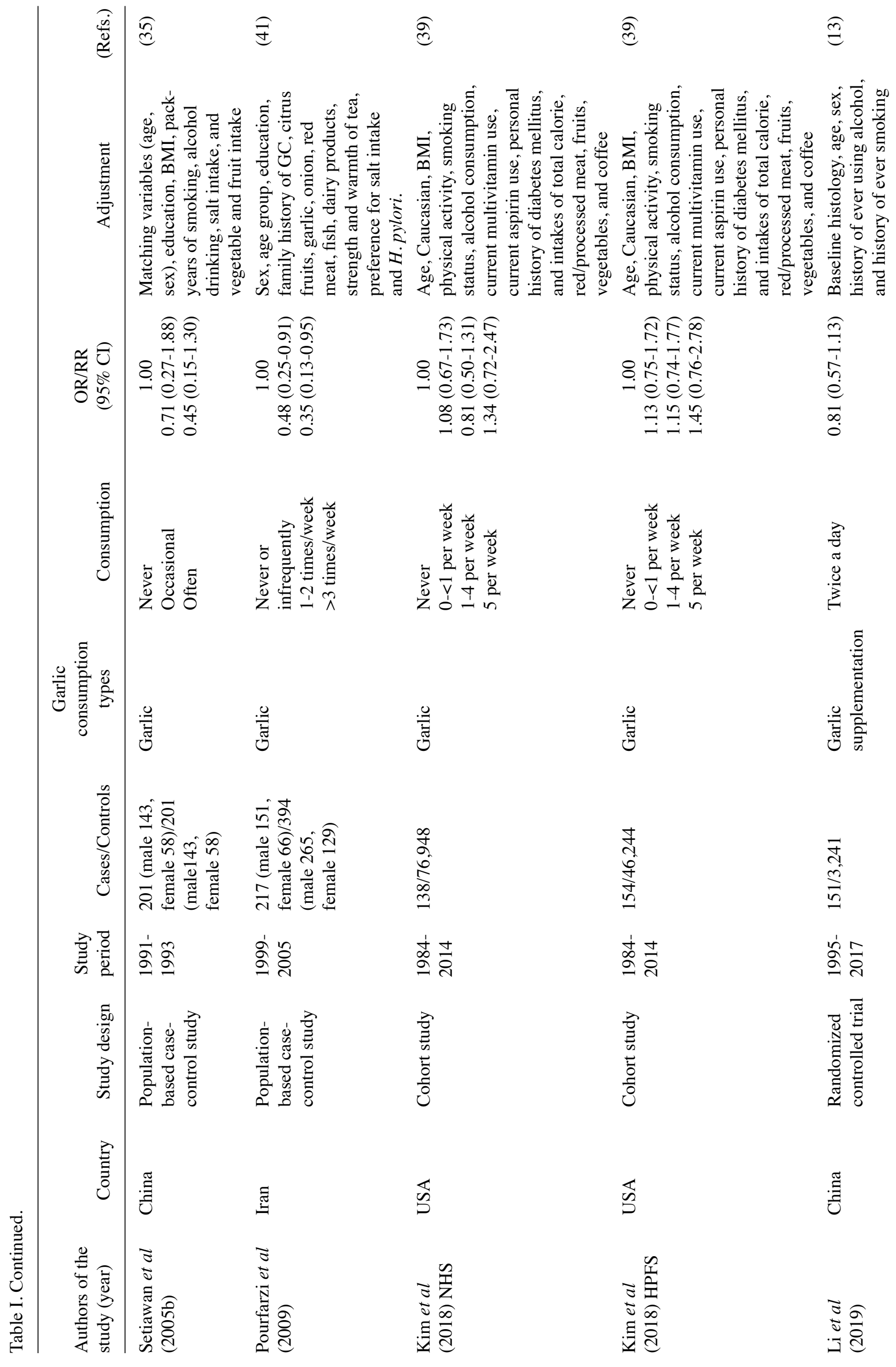




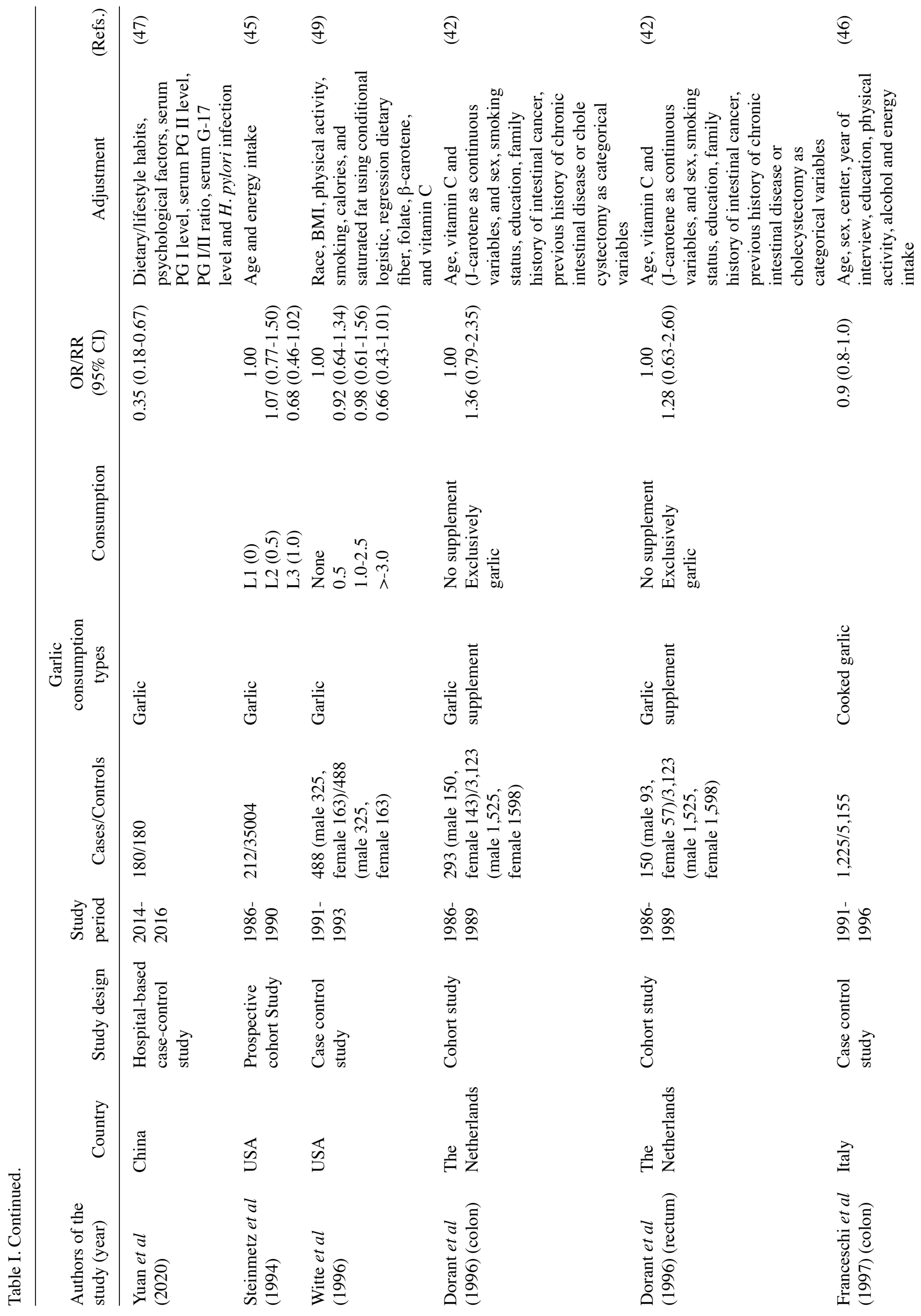




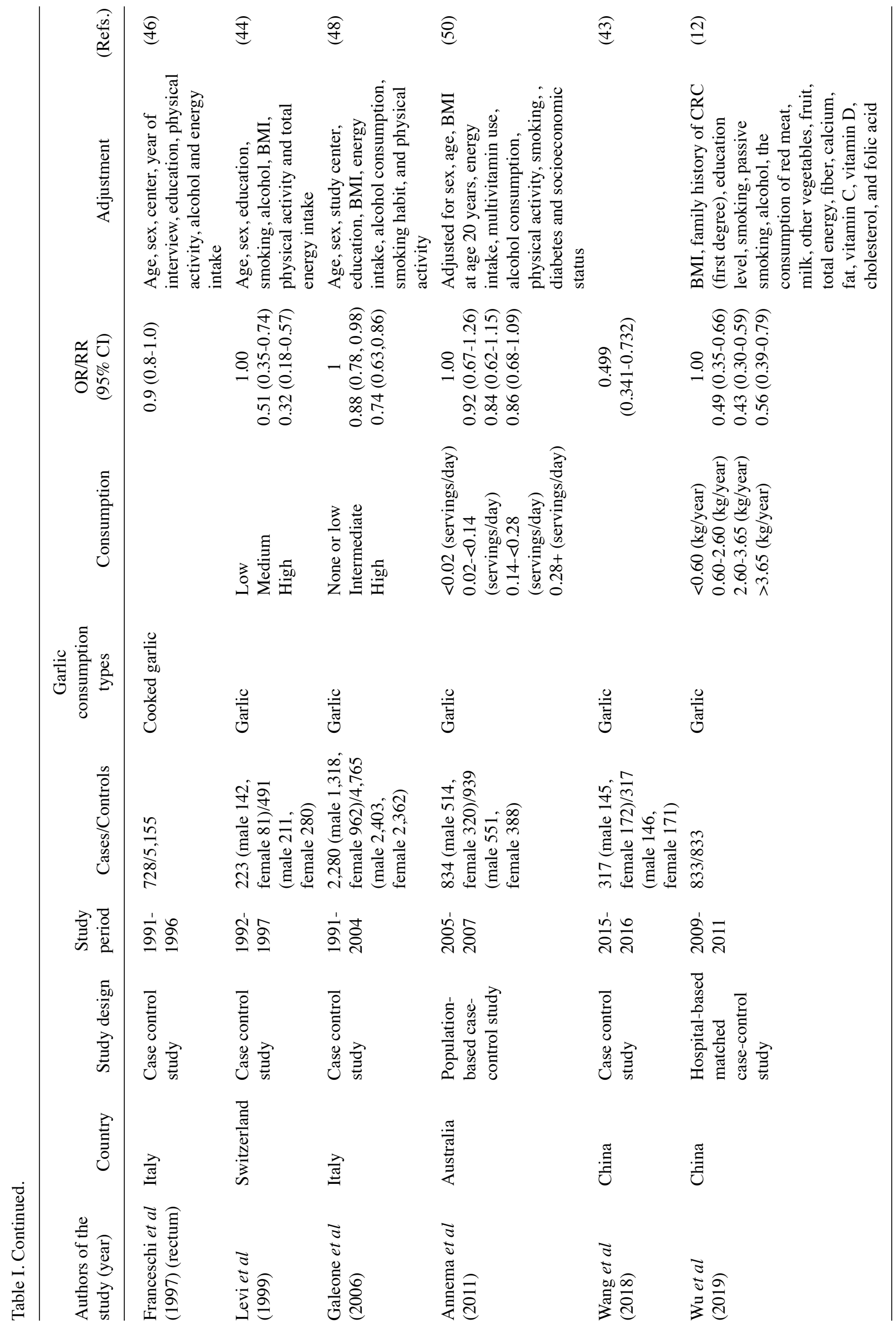


A Study

ES $(95 \% \mathrm{Cl})$

Yes vs No

Dorant et al, 1996 (152/3340)

De Stefani et al, 2001 (160/320)

Setiawan et al, 2005a (750/750)

Setiawan et al, 2005b (201/201)

Li et al, 2019 (151/3241)

Yuan et al, 2020 (180/180)

Subtotal $(I-$ squared $=38.9 \%, p=0.146$ )

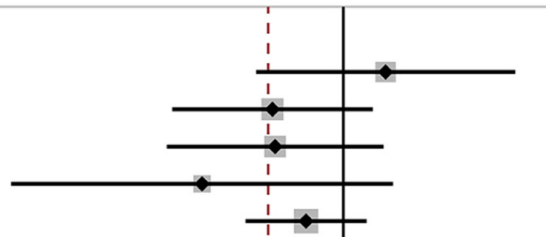

$1.27(0.61,2.64) \quad 6.65$

$0.67(0.38,1.18) \quad 8.08$

$0.68(0.37,1.25) \quad 7.66$

$0.45(0.15,1.32) \quad 4.39$

$0.81(0.58,1.14) \quad 10.14$

$0.35(0.18,0.68) \quad 7.28$

$0.68(0.50,0.93) \quad 44.20$

Every day vs No

Munoz et al, 2001 (292/485)

Takezaki et al, 2001 (187/333)

Subtotal (I-squared $=0.0 \%, p=0.472$ )

$\geq 3$ times/week vs No

Pourfarzi et al, 2009 (217/394)

Kim et al, 2018HPFS (138/6948)

Kimet al, 2018NHS (154/46244)

Subtotal (I-squared $=67.7 \%, p=0.045$ )

Others vs No

You et al, 1989 (564/1131)

Gao et al, 1999 (153/234)

Subtotal $(I-$ squared $=87.1 \%, p=0.005$ )

Overall $(I-$ squared $=69.8 \%, p=0.000)$

NOTE: Weights are from random effects analysis

0.129

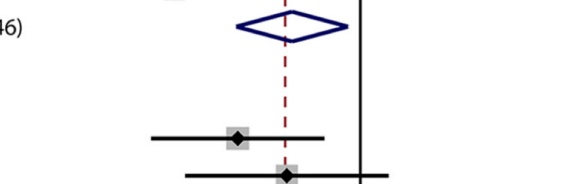

$0.50(0.31,0.82) \quad 8.78$

$0.66(0.37,1.17) \quad 8.00$

$0.56(0.39,0.82) \quad 16.78$

$0.35(0.13,0.95) \quad 4.85$

$1.45(0.76,2.77) \quad 7.35$

$1.34(0.72,2.48) \quad 7.63$

$0.97(0.46,2.04) \quad 19.84$

$0.70(0.44,1.11) \quad 9.08$

$0.31(0.22,0.44) \quad 10.10$

$0.46(0.21,1.02) \quad 19.18$

$0.65(0.49,0.87) \quad 100.00$

\begin{tabular}{cc|cc|c}
\multicolumn{1}{c}{} & & & 1 \\
0.129 & 0.65 & 1 & 7.72
\end{tabular}

B Study

$\%$

ID

$\mathrm{ES}(95 \% \mathrm{Cl})$

Weight

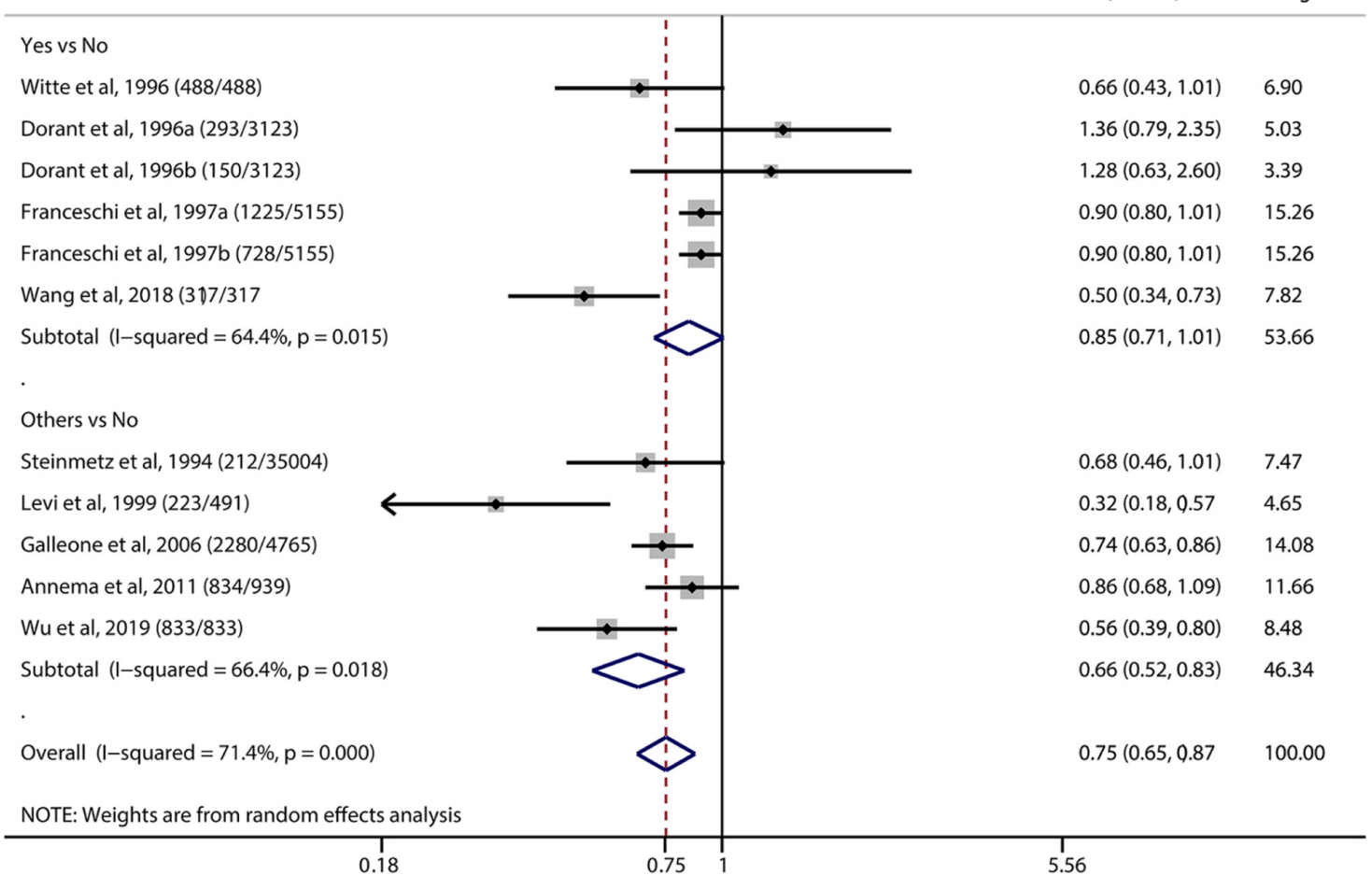

Figure 2. Associations between garlic intake and gastrointestinal cancer risk by garlic consumption. The (number/number) after each study in the figure indicates the (Cases/Controls). Vertical solid black line: invalid line; red dashed line: pooled effect size; horizontal black solid line: the width of the line represents the confidence interval (CI) of each study, the black diamond in the middle represents the OR of each study, and the gray square represents the weight of each study. Others: We have included some studies that differed from other classifications of garlic intake into this category. (A) Forest plots for the associations between garlic intake and gastric cancer risk by garlic consumption. The OR obtained by the pooled analysis was 0.65 ( $95 \%$ CI=0.49-0.87). (B) Forest plots for the associations between garlic intake and colorectal cancer risk by garlic consumption. The meta-analysis using the random-effects model showed a combined estimated OR of 0.75 (95\% CI=0.65-0.87), suggesting that garlic intake could reduce the risk of colorectal cancer. OR, odds ratio; ES, effect size. 


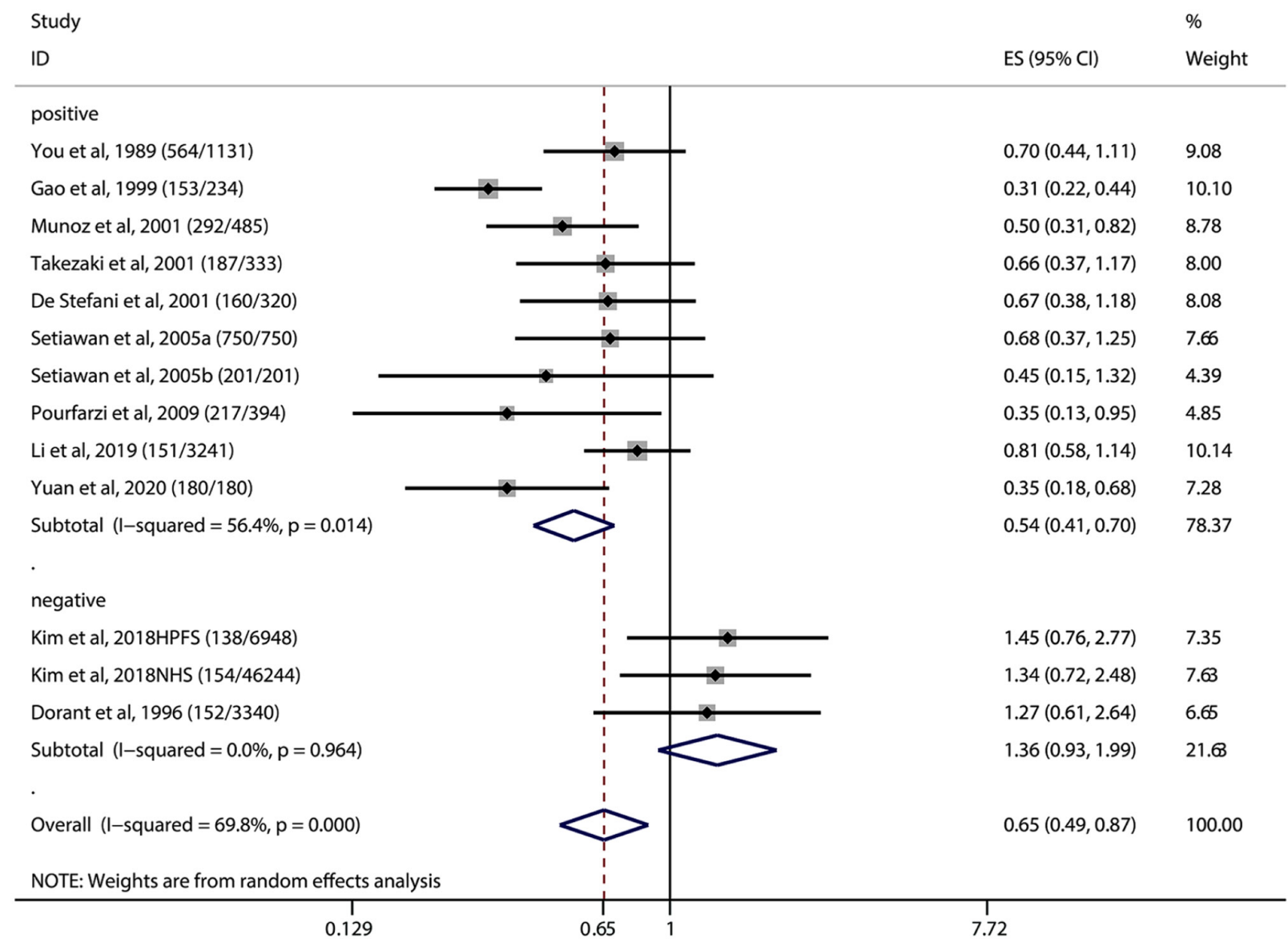

Figure 3. Positive and negative association studies between garlic intake and gastric cancer. The (number/number) after each study in the figure indicates the (Cases/Controls), Vertical solid black line: invalid line; red dashed line: pooled effect size; horizontal black solid line: the width of the line represents the confidence interval (CI) of each study, the black diamond in the middle represents the OR of each study, and the gray square represents the weight of each study. Among the 11 included studies, 2 studies showed that garlic intake had no association with the incidence of gastric cancer $(\mathrm{OR}=1.36,95 \% \mathrm{CI}=0.93-1.99)$, including 12,6976 subjects, and 9 studies showed that garlic intake could reduce the incidence of gastric cancer $(\mathrm{OR}=0.54,95 \% \mathrm{CI}=0.41-0.70)$, including 9,944 subjects. OR, odds ratio; ES, effect size.

meta-analysis. The OR obtained by the pooled analysis was $0.65(95 \% \mathrm{CI}=0.49-0.87, \mathrm{P}<0.001)$, indicating that garlic intake was associated with a lower risk of gastric cancer in individuals compared with those without garlic intake (Fig. 2A). Participants who consumed garlic every day had a significant lower risk of gastric cancer than those who did not consume garlic.

In the subgroup analysis by geographic area (Fig. S1), the estimated OR of the studies in Asia, Europe and America was 0.53 (95\% CI=0.38-0.73), 1.27 (95\% CI=0.61-2.64), 0.87 (95\% CI=0.52-1.47, P<0.05), respectively (Table SIV). In addition, the comprehensive analysis of prospective studies showed that garlic intake correlated with a small reduction in gastric cancer $(\mathrm{OR}=1.07,95 \% \mathrm{CI}=0.79-1.47)$, while the retrospective studies showed garlic intake had a more significant effect $(\mathrm{OR}=0.50,95 \% \mathrm{CI}=0.39-0.64)$ (Fig. S2).

We found that among those 11 included studies, 2 studies $(36,39)$ containing 126,976 subjects showed that garlic intake had no significant association with the incidence of gastric cancer $(\mathrm{OR}=1.36,95 \% \mathrm{CI}=0.93-1.99)$, while 9 studies $(13,18,34,35,37,38,40,41,47)$ containing 9,944 subjects showed that garlic intake could significantly reduce the incidence of gastric cancer $(\mathrm{OR}=0.54,95 \% \mathrm{CI}=0.41-0.70)$ $(\mathrm{P}<0.05)$ (Fig. 3).
A total of 9 studies estimated the association between garlic intake and the risk of colorectal cancer (Fig. 2B). The meta-analysis using the random-effects model showed a combined estimated OR of 0.75 (95\% CI=0.65-0.87, $\mathrm{P}<0.001)$, suggesting that garlic intake could significantly reduce the risk of colorectal cancer. Among the 9 included research studies, only Dorant et al (42) and Franceschsi et al (46) estimated the OR values for colon cancer and rectal cancer separately, without providing the total OR value.

Compared to the retrospective studies $(\mathrm{OR}=0.72$, 95\% $\mathrm{CI}=0.62-0.84, \mathrm{P}<0.001)$, the results of the prospective study $(\mathrm{OR}=1.01,95 \% \mathrm{CI}=0.62-1.65, \mathrm{P}<0.1)$ showed an insignificant effect of garlic intake on reducing the risk of colorectal cancer (Table SV; Fig. S3). Subgroup analyses of geographical regions (Fig. S4) showed that garlic intake significantly reduced the risk of colorectal cancer in Asia compare to other regions.

Heterogeneity assessment and sensitivity analysis. The random effect model suggested a strong heterogeneity with $\mathrm{I}^{2}=69.8 \%$, and $\mathrm{P}<0.1$ in the studies of garlic and gastric cancer which were selected for the meta-analysis. Therefore, we conducted Galbraith test to further identify the source of heterogeneity. The result of Galbraith test showed that the studies of Gao et al (40) and Kim et al (39) were the main 
A

$\mathrm{b} / \mathrm{se}(\mathrm{b})$

Fitted values

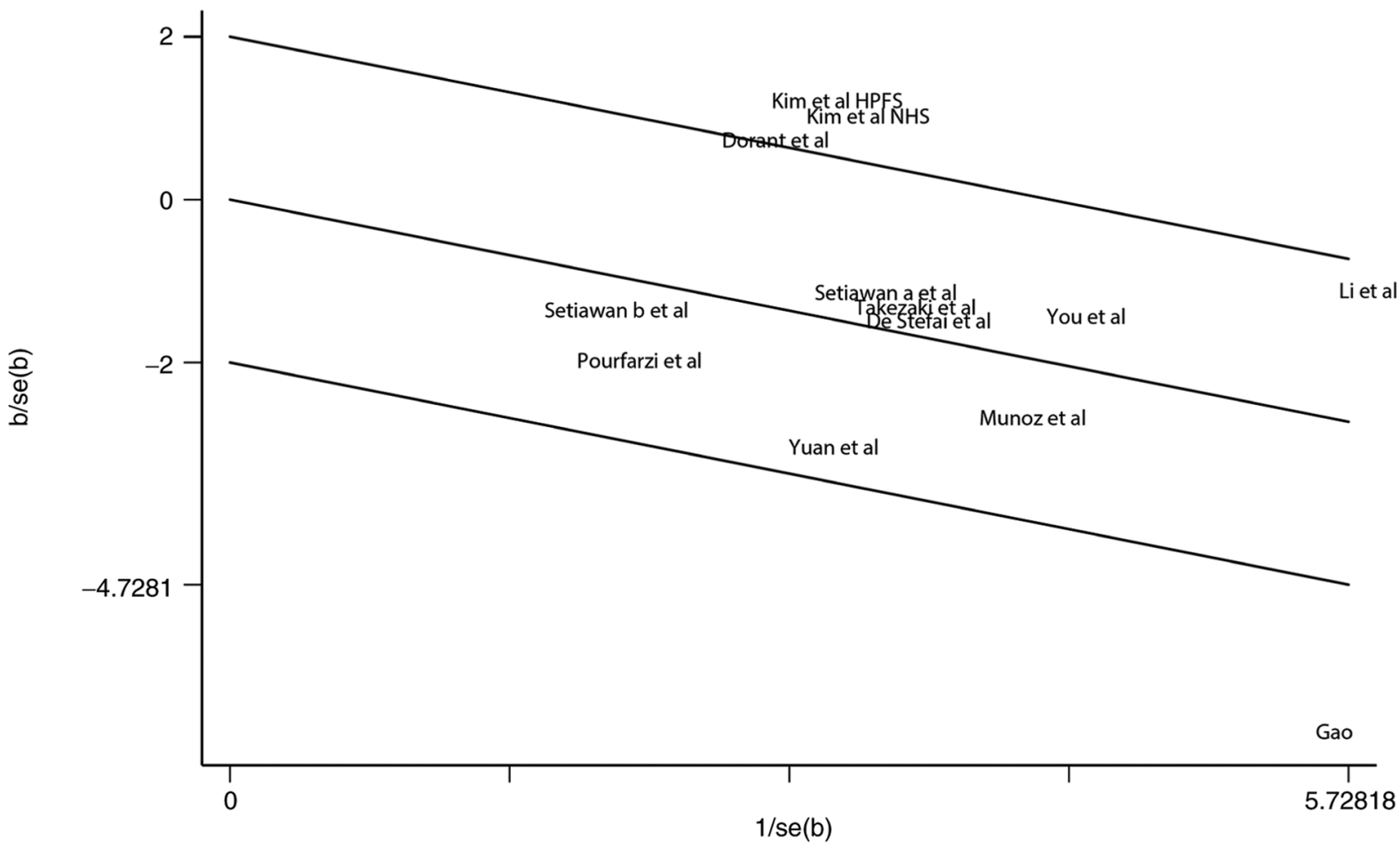

B

$\mathrm{b} / \mathrm{se}(\mathrm{b})$

Fitted values

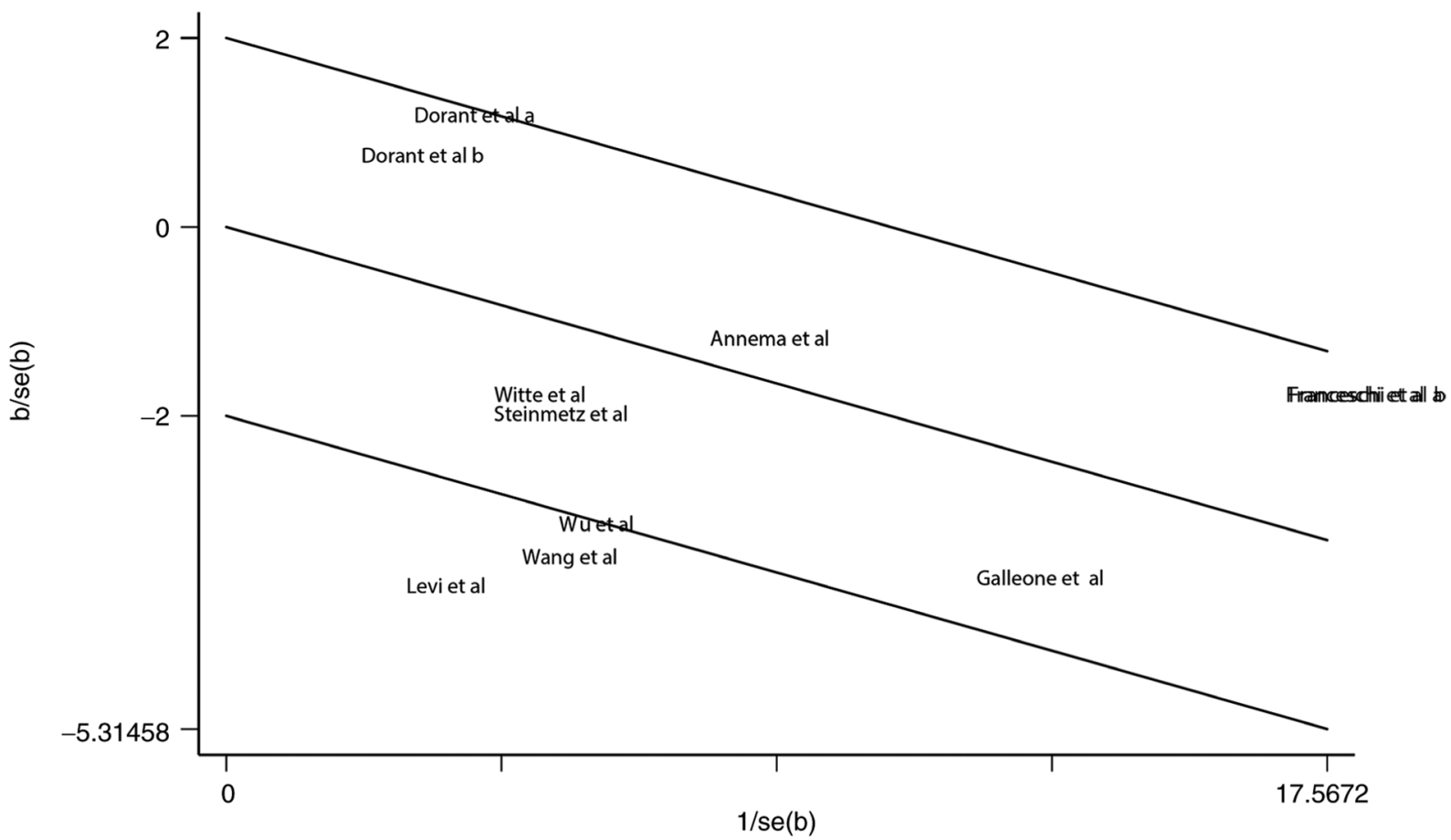

Figure 4. Source of heterogeneity in the meta-analysis of garlic intake and gastrointestinal cancer risk. (A) The Galbraith test indicating the source of heterogeneity in the meta-analysis of garlic intake and gastric cancer risk. The studies of Gao et al (1999) and Kim et al (2018) were the main sources of heterogeneity. (B) The Galbraith test indicating the source of heterogeneity in the meta-analysis of garlic intake and colorectal cancer risk. The results indicate that 3 studies (Wu et al, Levi et al, and Wang et al) were the main sources of heterogeneity.

sources of heterogeneity (Fig. 4A). The result of sensitivity analysis showed that our results were stable, and there was no significant difference in the pooled results (Fig. 5A).
For the 9 studies of garlic and colorectal cancer, a significant heterogeneity was also suggested $\left(\mathrm{I}^{2}=71.4 \%, \mathrm{P}<0.001\right)$. According to the results of Galbraith test, three studies 
A
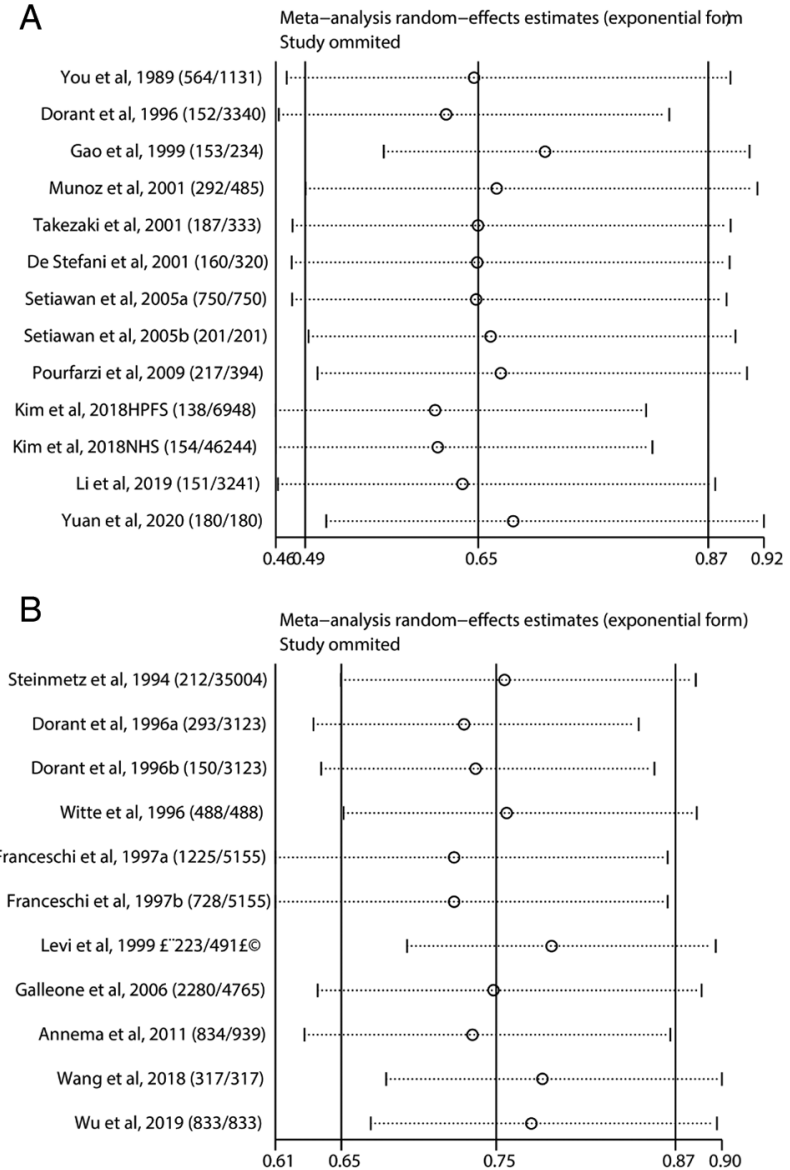

Figure 5. Sensitivity analysis of garlic and gastrointestinal cancer (A) Sensitivity analysis of garlic and gastric cancer. No significant differences were found among the studies. (B) Sensitivity analysis of garlic intake and colorectal cancer. The results of the sensitivity analysis showed that no articles exceeded the limits and there were no significant differences among the studies.

[Wu et al (12), Levi et al (44) and Wang et al (43)] were indicated as the main sources of heterogeneity (Fig. 4B). Sensitivity analysis was used to estimate the impact of each study on the overall estimate (Fig. 5B). The results of the sensitivity analysis showed that no articles exceeded the limits and there were no significant differences among the studies. Our meta-analysis suggested that garlic can reduce the risk of gastrointestinal cancers, and most of the included studies are consistent with this conclusion (Fig. 6).

Risk of bias assessment. A randomized controlled trial evaluated by the Cochrane risk assessment tool was rated as low risk, and the non-randomized controlled trials were scored using a NOS scale, as shown in Table SVI and Table SVII.

Publication bias. Potential publication bias was assessed using the Begg (Fig. 7) and Egger tests (Table SVIII). There was no significant evidence of publication bias for gastric and colorectal cancers.

\section{Discussion}

This meta-analysis combined the results of 20 studies regarding the association of garlic consumption with gastric cancer (11 studies) and colorectal cancer (9 studies). Our results indicated that garlic intake significantly reduces the risk of gastric cancer $(\mathrm{OR}=0.65,95 \% \mathrm{CI}=0.49-0.87, \mathrm{P}<0.001)$ and colorectal cancer $(\mathrm{OR}=0.75,95 \% \mathrm{CI}=0.65-0.87, \mathrm{P}<0.001)$, consistent with the epidemiological evidence supporting the correlation between garlic intake and a reduced risk of gastric and colorectal cancer. The results of the geographical subgroup analysis showed that a greater risk reduction occurs in the Asian region compared with other geographical regions. We suspect one of the possible reasons is that garlic consumption is higher in Asia, especially in China, where the habit of eating raw garlic leads to a higher consumption than other countries in the world $(51,52)$. Some studies have also analyzed the effects of allium and onion on gastrointestinal tumors. We speculate that the active ingredients may be the same or similar to garlic, and that these foods may have a superimposed effect on gastrointestinal cancers $(12,18,38,40,41)$. In addition, the European population may be under-represented since there was only one study conducted in Europe. Our meta-analysis incorporated the results of the latest research by Li et al (13) and summarized the recent studies. Although most of the included studies were retrospective case-control studies, lacking blinding and randomized control (53), we still found that garlic intake was associated with a reduced risk of gastric and colorectal cancer. Compared to the previous meta-analysis on the relationship between garlic and gastric and colorectal cancer by Fleischauer et al (28), our meta-analysis included more studies and conducted a subgroup analysis with a focus on garlic intake, resulting in more reliable conclusions. Due to the various dietary patterns in the different studies, we cannot exclude the effects of other factors, such as vegetable and fiber intake. Additionally, each study had different confounding factors, and most studies adjusted them, such as sex, age, and others. From the results of the subgroup analysis, it was shown that the intake of garlic can reduce the likelihood of gastric cancer compared with the non-intake of garlic. Although a previous meta-analysis by others showed that the protective effect of garlic on gastric and colorectal cancer may be overestimated (28), the results of the comprehensive analysis in this study indicated the preventive function of garlic in gastrointestinal tumors.

A further review was conducted on the molecular mechanisms of the anticancer effects of garlic (Fig. 8). Based on previous literature, garlic contains a variety of organic sulfur compounds, mainly including S-allylmercaptocysteine (SAMC), diallyl disulfide (DADS), diallyl trisulfide (DATS) and allicin, which are the main components which produce potential antitumor effects. We searched the Pubmed database with key terms including 'gastrointestinal tumors', 'garlic', 'mechanism', 'pathways', and reviewed biological functions of these four organic sulfur compounds. These organic sulfur compounds demonstrate potential antitumor activity through various underlying mechanisms. First, organic sulfur compounds can regulate the cell cycle. DADS and DATS can activate the P53/P21 pathway, while DADS can inhibit the expression of cyclin B1, cdc2, and cdc25c proteins, leading to $\mathrm{G} 2 / \mathrm{M}$ phase arrest in tumor cells $(54,55)$. SAMC and DADS can inhibit the polymerization of tubulin and thus affect the function of the spindle, resulting in mitotic arrest (56). In addition, allicin induces cell cycle arrest in the 


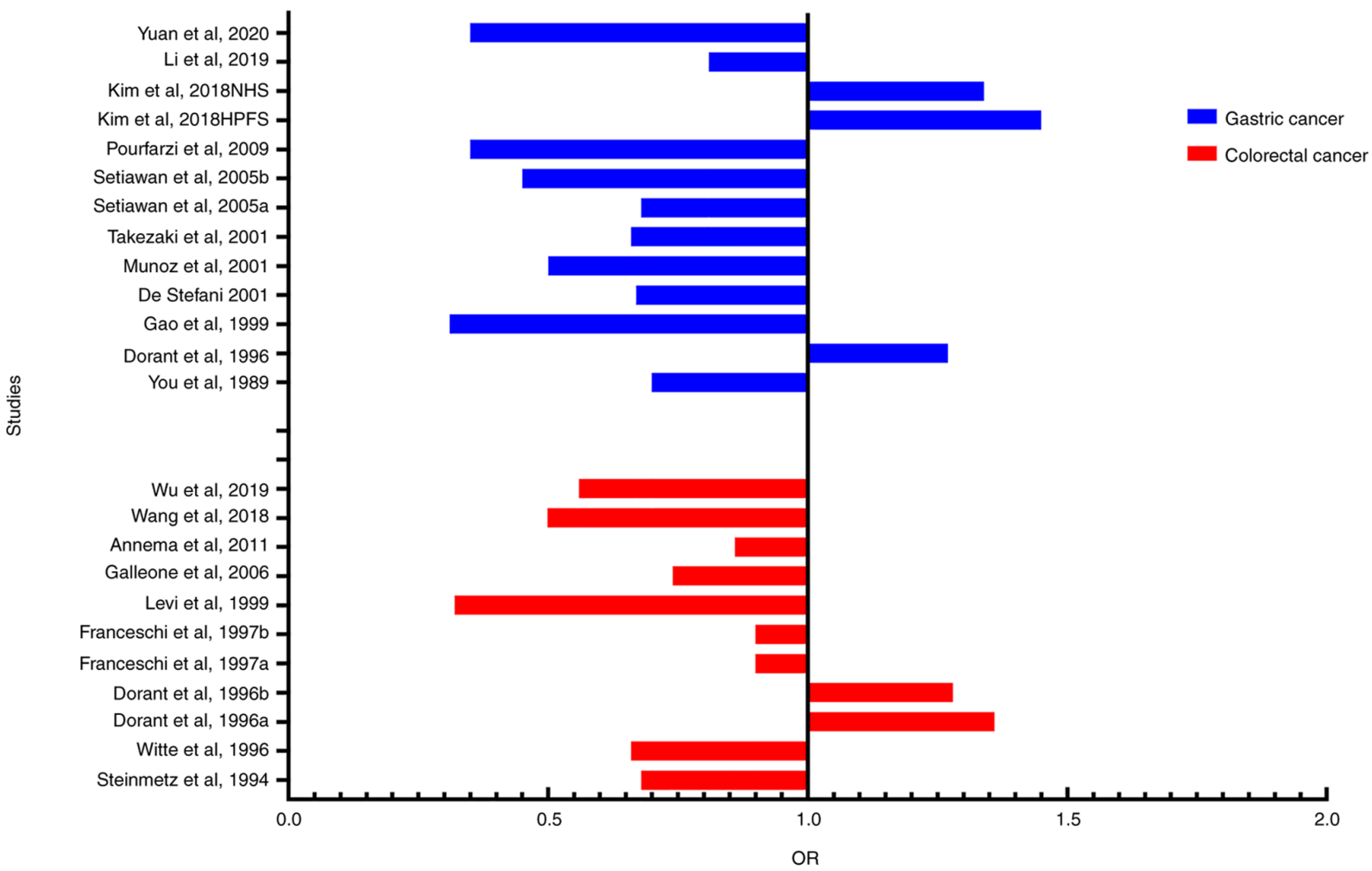

Figure 6. Relationship between included studies and risk of gastrointestinal cancer by garlic intake. In all the included studies, the results of most studies indicated that garlic can reduce the risk of gastrointestinal cancers. OR, odds ratio.

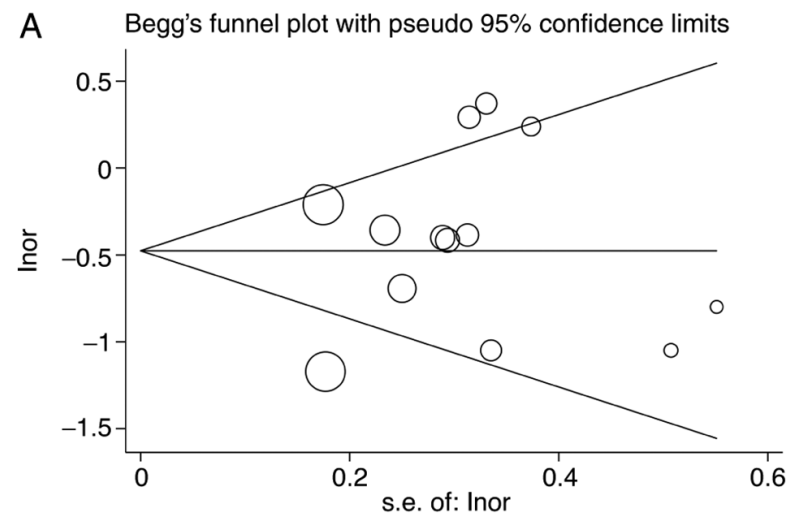

B Begg's funnel plot with pseudo $95 \%$ confidence limits

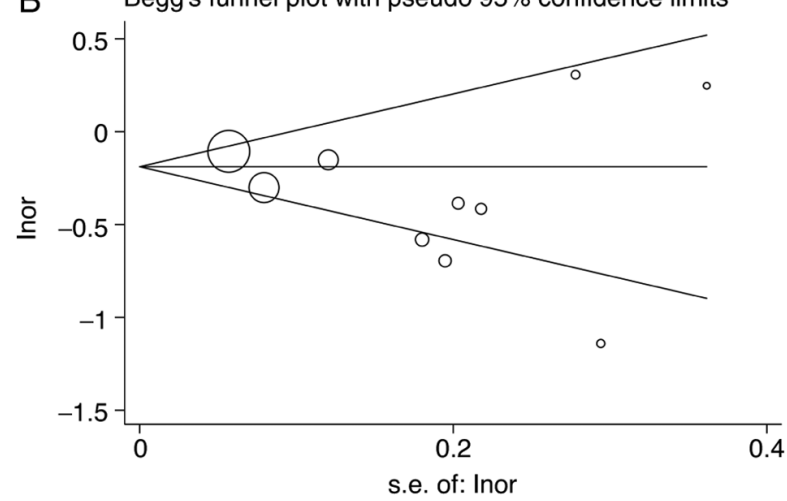

Figure 7. Potential publication bias assessed by Begg's test. Funnel plot indicating the publication bias in the studies included in the meta-analysis of the garlic intake and gastrointestinal cancers. There was no significant evidence of publication bias for gastric and colorectal cancers. (A) Begg's funnel plot for garlic intake and gastric cancer. (B) Begg's funnel plot for garlic intake and colorectal cancer.
S phase of the cell cycle (57). Second, organic sulfides can induce cell apoptosis in the following ways. DADS, DATS, SAMC and allicin promote the release of cytochrome $c$ from mitochondria, thereby activating caspase family proteins, such as caspase 3 and caspase 9, and inducing apoptosis $(23,56,58-62)$; DADS, DATS and SAMC can activate the p53 pathway, resulting in the decreased expression of Bcl-2 and increased expression of Bax (54,58,63-65); SAMC and DATS significantly activate three pathways of the MAPKs pathway, including ERK, JNK and p38 $(63,64)$; Moreover, DATS can significantly upregulate the level of glycogen synthase kinase $3 \beta$ (GSK3 $\beta$ ) to increase the digestion of $\beta$-catenin, indicating that DATS can inhibit the Wnt/ $\beta$-catenin pathway, a key component in the occurrence and development of tumors. DATS can also increase reactive oxygen species (ROS) production and activate the AMPK pathway $(23,55)$; Allicin can reduce phosphorylated signal transducer and activator of transcription 3 (STAT3) to inhibit the STAT3 pathway, as well as activate Nrf2 and induce its translocation to the nucleus $(66,67)$. Third, DADS can inhibit matrix metalloproteinase (MMP)-2, MMP-9, tissue inhibitor of metalloproteinases-1 (TIMP-1), TIMP-2 and PI3K/AKT pathways to inhibit cell metastasis (68).

To summarize, DADS, DATS, SAMC, and allicin participate in tumor-related biological process through various mechanisms, eventually leading to apoptosis, cell cycle arrest, and migration inhibition in tumor cells. A medical compound containing active ingredients from garlics may exert potential tumor preventive or therapeutic effects through the above-mentioned mechanisms in the human body, representing a novel antitumor treatment alternative. 
A

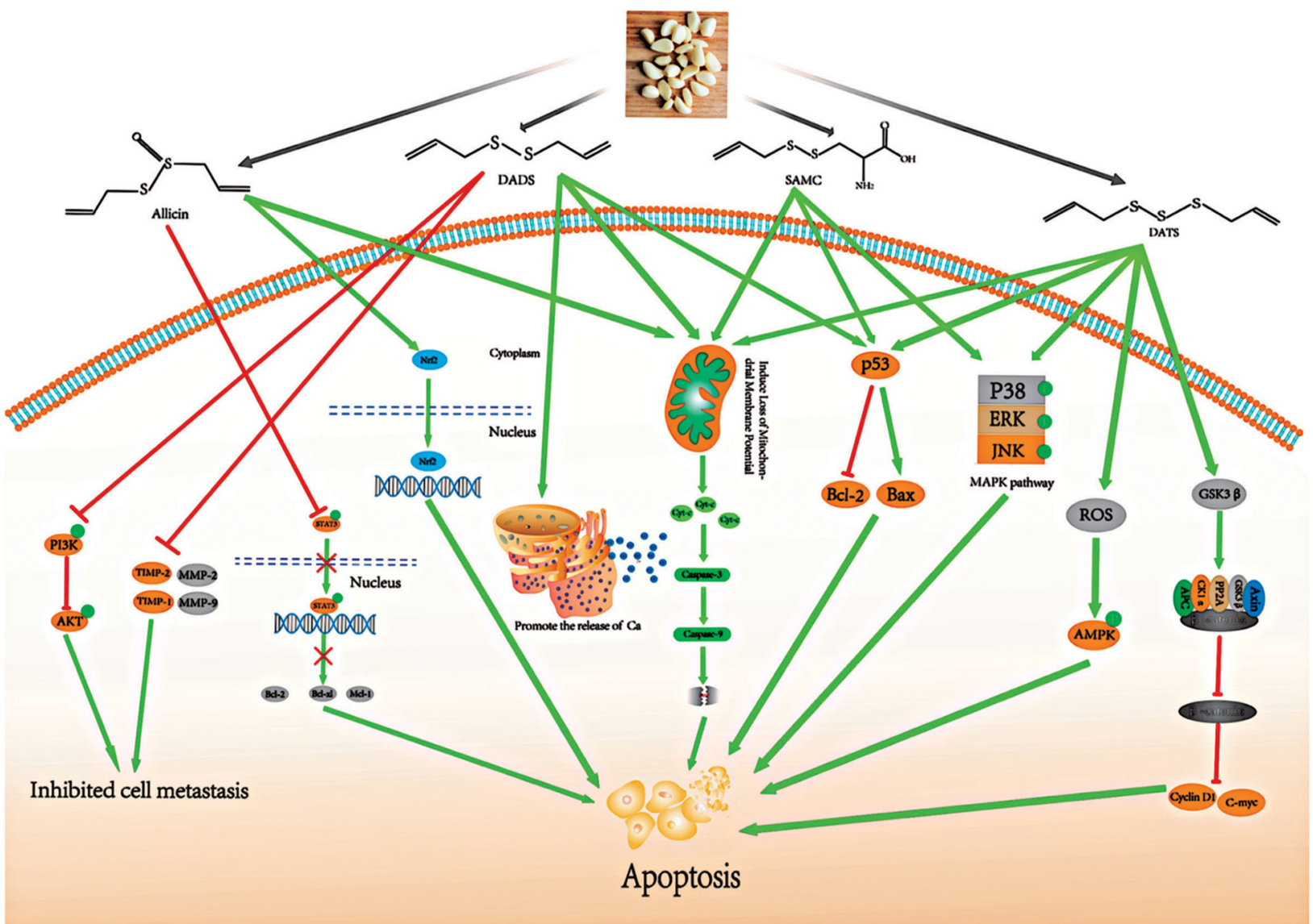

B

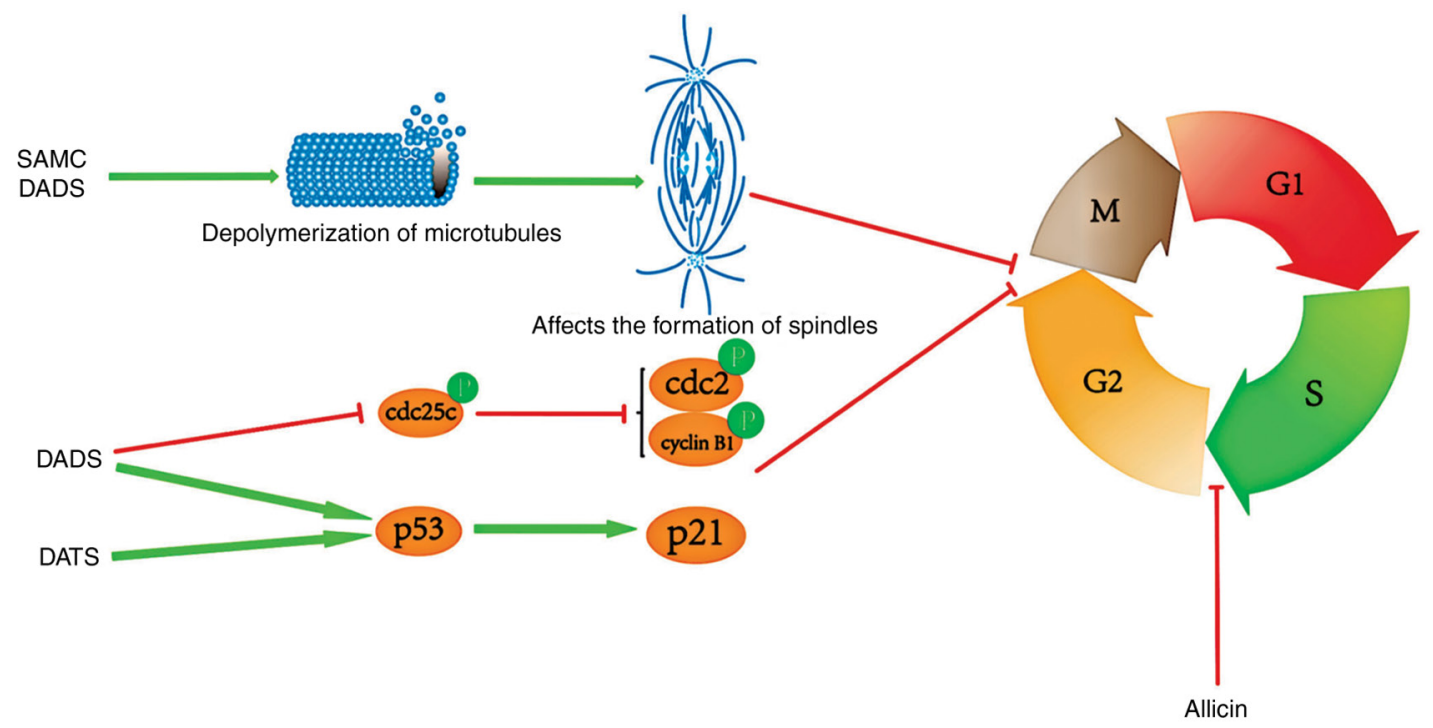

Figure 8. Potential molecular mechanisms of the anticancer effects of garlic. (A) DADS, DATS, SAMC and allicin can all promote the release of cytochrome $c$ from mitochondria, thereby activating the caspase family proteins, such as caspase 3 and caspase 9 , and inducing apoptosis; DADS, DATS and SAMC can activate the 553 pathway, resulting in decreased expression of Bcl-2 and increased expression of Bax. SAMC and DATS significantly activated the three pathways of MAPKs, including ERK, JNK and p38. In addition, the Wnt/ $\beta$-catenin pathway plays a key role in the occurrence and development of tumors, DATS can significantly upregulate the level of GSK $3 \beta$, thereby increasing the digestion of $\beta$-catenin, indicating that DATS can inhibit the Wnt/ $\beta$-catenin pathway. DATS can also increase ROS production and activate the AMPK pathway. Allicin can reduce phosphorylated STAT3, thereby inhibiting the STAT3 pathway, and allicin can also activates Nrf2 and induces its translocation to the nucleus. Moreover, DADS can inhibit MMP-2 and MMP-9. (B) DADS and DATS can activate the P53/P21 pathway, and DADS can also inhibit the expression of cyclin B1, cdc2, and cdc25c proteins, leading to G2/M phase arrest of tumor cells. SAMC and DADS can affect the polymerization of tubulin and thus affect the function of the spindle, leading to mitotic arrest. Finally, allicin induces cell cycle arrest in the S phase. DADS, diallyl disulfide; DATS, diallyl trisulfide; SAMC, S-allylmercaptocysteine; GSK3 $\beta$, glycogen synthase kinase $3 \beta$; ROS, reactive oxygen species; STAT3, signal transducer and activator of transcription 3; MMP, matrix metalloproteinase.

This meta-analysis has the following limitations. i) Only a small set of randomized controlled trials are included in the date, most of which are case-control and cohort studies. Compared with randomized controlled trials, case-control and 
cohort studies have more unaccounted parameters in blind control and follow-up, resulting in higher propensity of bias. ii) This meta-analysis included studies conducted in different countries since the 1990s. Not all studies were primarily based on onion vegetables, and there was inconsistent stratification among the studies. iii) Most of the included studies were conducted in China, where the incidence of gastric cancer is generally higher than the rest of the world. Moreover, garlic intake is relatively high in the diet of Chinese people. iv) Many studies did not control other diets, and the type of garlic consumption remains unstandardized. It is difficult to determine the minimum garlic intake for a tumor-protective effect. The minimum and maximum consumption levels varied greatly among the different studies.

The quantified $\mathrm{I}^{2}$ test showed that the included studies had significant heterogeneity, and Galbraith test suggested that some studies might be the sources. Therefore, we explored the possible cause for the heterogeneity. First, most of the included studies were retrospective studies with various confounding factors, and recall bias may have produced different results from the prospective studies. Second, most studies had collected data in the form of questionnaires instead of objective measurement. Third, studies conducted in Asia, especially in China, where garlic is a highly consumed food, may lead to certain bias on the results when pooled together with studies conducted in other places with much lower garlic consumption.

In summary, our meta-analysis provides strong evidence that garlic can reduce the risk of gastric and colorectal cancers. The conclusion was mainly based on case-control studies with many potential confounders, and further research is warranted to validate it.

\section{Acknowledgements}

Not applicable.

\section{Funding}

The present work was financially supported by grants from the National Natural Science Foundation of China [32000098, 31671468], the China Postdoctoral Science Foundation [2020M682167, 2020T130070ZX], the Science and Technology Development Plan of Jinan Municipal Health Commission [2020-3-09], Jinan 2020 Science and Technology Innovation Development Plan [202019035], and the Academic Promotion Programme of Shandong First Medical University [2019QL024].

\section{Availability of data and materials}

The study was registered in PROSPERO (CRD42020179464).

\section{Authors' contributions}

HJL designed the review and meta-analysis. YYW and HJL conceived and wrote the review. YFW and DRL acquired and analysed the data. MYJ and PH analyzed and confirmed the integrity of the data found in the literature. YSW was involved in drafting the manuscript. All authors contributed to the analysis, reviewed the results and read and approved the final manuscript.

\section{Ethics approval and consent to participate}

Not applicable.

\section{Patient consent for publication}

Not applicable.

\section{Authors' information}

ORCID: Huanjie Li, orcid.org/0000-0002-4997-0927; Yunshan Wang, orcid.org/0000-0003-3767-6728.

\section{Competing interests}

The authors declare that they have no competing interests.

\section{References}

1. Ferlay J, Soerjomataram I, Dikshit R, Eser S, Mathers C, Rebelo M, Parkin DM, Forman D and Bray F: Cancer incidence and mortality worldwide: Sources, methods and major patterns in GLOBOCAN 2012. Int J Cancer 136: E359-E386, 2015.

2. Gausman V, Dornblaser D, Anand S, Hayes RB, O'Connell K, Du M and Liang PS: Risk factors associated with early-onset colorectal cancer. Clin Gastroenterol Hepatol 18: 2752-2759.e2, 2020.

3. Bray F, Ferlay J, Soerjomataram I, Siegel RL, Torre LA and Jemal A: Global cancer statistics 2018: GLOBOCAN estimates of incidence and mortality worldwide for 36 cancers in 185 countries. CA Cancer J Clin 68: 394-424, 2018.

4. Zhou X, Qian H, Zhang D and Zeng L: Garlic intake and the risk of colorectal cancer: A meta-analysis. Medicine (Baltimore) 99: e18575, 2020.

5. Larsson SC, Orsini N and Wolk A: Processed meat consumption and stomach cancer risk: A meta-analysis. J Natl Cancer Inst 98: 1078-1087, 2006.

6. Sugano K: Effect of Helicobacter pylori eradication on the incidence of gastric cancer: A systematic review and meta-analysis. Gastric Cancer 22: 435-445, 2019.

7. Park HK, Lee Y, Kang BW, Kwon KI, Kim JW, Kwon OS, Cobb LK, Campbell NRC, Blakeman DE and Kim CI: Progress on sodium reduction in South Korea. BMJ Glob Health 5: e002028, 2020.

8. Lee HS, Duffey KJ and Popkin BM: Sodium and potassium intake patterns and trends in South Korea. J Hum Hypertens 27: 298-303, 2013.

9. Ford AC, Yuan Y and Moayyedi P: Helicobacter pylori eradication therapy to prevent gastric cancer: Systematic review and meta-analysis. Gut 69: 2113-2121, 2020.

10. Hooi JKY, Lai WY, Ng WK, Suen MMY, Underwood FE, Tanyingoh D, Malfertheiner P, Graham DY, Wong VWS, Wu JCY, et al: Global prevalence of Helicobacter pylori infection: Systematic review and meta-Analysis. Gastroenterology 153: 420-429, 2017.

11. Hou N, Huo D and Dignam JJ: Prevention of colorectal cancer and dietary management. Chin Clin Oncol 2: 13, 2013.

12. Wu X, Shi J, Fang WX, Guo XY, Zhang LY, Liu YP and Li Z: Allium vegetables are associated with reduced risk of colorectal cancer: A hospital-based matched case-control study in China. Asia Pac J Clin Oncol 15: e132-e141, 2019.

13. Li WQ, Zhang JY, Ma JL, Li ZX, Zhang L, Zhang Y, Guo Y, Zhou T, Li JY, Shen L, et al: Effects of Helicobacter pylori treatment and vitamin and garlic supplementation on gastric cancer incidence and mortality: Follow-up of a randomized intervention trial. BMJ 366: 15016, 2019.

14. Li Z, Ying X, Shan F and Ji J: The association of garlic with helicobacter pylori infection and gastric cancer risk: A systematic review and meta-analysis. Helicobacter 23: e12532, 2018.

15. Nicastro HL, Ross SA and Milner JA: Garlic and onions: Their cancer prevention properties. Cancer Prev Res (Phila) 8: 181-189, 2015. 
16. Desai G, Schelske-Santos M, Nazario CM, Rosario-Rosado RV, Mansilla-Rivera I, Ramírez-Marrero F, Nie J, Myneni AA, Zhang ZF, Freudenheim JL and Mu L: Onion and garlic intake and breast cancer, a case-control study in Puerto Rico. Nutr Cancer 72: 791-800, 2020.

17. Chan JM, Wang F and Holly EA: Vegetable and fruit intake and pancreatic cancer in a population-based case-control study in the San Francisco bay area. Cancer Epidemiol Biomarkers Prev 14 2093-2097, 2005.

18. Takezaki T, Gao CM, Wu JZ, Ding JH, Liu YT, Zhang Y, Li SP, Su P, Liu TK and Tajima K: Dietary protective and risk factors for esophageal and stomach cancers in a low-epidemic area for stomach cancer in Jiangsu Province, China: Comparison with those in a high-epidemic area. Jpn J Cancer Res 92: 1157-1165, 2001.

19. You WC, Chang YS, Heinrich J, Ma JL, Liu WD, Zhang L, Brown LM, Yang CS, Gail MH, Fraumeni JF Jr and Xu GW: An intervention trial to inhibit the progression of precancerous gastric lesions: Compliance, serum micronutrients and S-allyl cysteine levels, and toxicity. Eur J Cancer Prev 10: 257-263, 2001

20. Wang HR, Pan YM and Zhang L: Mechanism for allicin to sensitize gastric cancer cells to chemotherapy. World Chinese J Digestol 27: 1248-1255, 2019.

21. Wu S and Li Z: Effect of allicin on the proliferation and apoptosis of gastric cancer cells SGC-7901 through inhibiting autophagy of endoplasmic reticulum. Anti-Tumor Pharmacy 9: 226-230, 2019.

22. Arreola R, Quintero-Fabián S, López-Roa RI Flores-Gutiérrez EO, Reyes-Grajeda JP, Carrera-Quintanar L and Ortuño-Sahagún D: Immunomodulation and anti-inflammatory effects of garlic compounds. J Immunol Res 2015: 401630, 2015

23. Yu CS, Huang AC, Lai KC, Huang YP, Lin MW, Yang JS and Chung JG: Diallyl trisulfide induces apoptosis in human primary colorectal cancer cells. Oncol Rep 28: 949-954, 2012.

24. Zhu B, Zou L, Qi L, Zhong R and Miao X: Allium vegetables and garlic supplements do not reduce risk of colorectal cancer, based on meta-analysis of prospective studies. Clin Gastroenterol Hepatol 12: 1991-2001.e1-4; quiz e121, 2014.

25. Turati F, Guercio V, Pelucchi C, La Vecchia C and Galeone C: Colorectal cancer and adenomatous polyps in relation to allium vegetables intake: A meta-analysis of observational studies. Mol Nutr Food Res 58: 1907-1914, 2014.

26. Kodali RT and Eslick GD: Meta-analysis: Does garlic intake reduce risk of gastric cancer? Nutr Cancer 67: 1-11, 2015.

27. $\mathrm{Hu} \mathrm{JY}, \mathrm{Hu}$ YW, Zhou JJ, Zhang MW, Li D and Zheng S: Consumption of garlic and risk of colorectal cancer: An updated meta-analysis of prospective studies. World J Gastroenterol 20: 15413-15422, 2014.

28. Fleischauer AT, Poole C and Arab L: Garlic consumption and cancer prevention: Meta-analyses of colorectal and stomach cancers. Am J Clin Nutr 72: 1047-1052, 2000.

29. Chiavarini M, Minelli L and Fabiani R: Garlic consumption and colorectal cancer risk in man: A systematic review and meta-analysis. Public Health Nutr 19: 308-317, 2016.

30. Turati F, Pelucchi C, Guercio V, La Vecchia C and Galeone C: Allium vegetable intake and gastric cancer: A case-control study and meta-analysis. Mol Nutr Food Res 59: 171-179, 2015.

31. Meng S, Zhang X, Giovannucci EL, Ma J, Fuchs CS and Cho E: No association between garlic intake and risk of colorectal cancer. Cancer Epidemiol 37: 152-155, 2013.

32. Higgins JP, Altman DG, Gøtzsche PC, Jüni P, Moher D, Oxman AD, Savovic J, Schulz KF, Weeks L, Sterne JAC, et al: The cochrane collaboration's tool for assessing risk of bias in randomised trials. BMJ 343: d5928, 2011.

33. Stang A: Critical evaluation of the Newcastle-Ottawa scale for the assessment of the quality of nonrandomized studies in meta-analyses. Eur J Epidemiol 25: 603-605, 2010.

34. De Stefani E, Correa P, Boffetta P, Ronco A, Brennan P, Deneo-Pellegrini $\mathrm{H}$ and Mendilaharsu M: Plant foods and risk of gastric cancer: A case-control study in Uruguay. Eur J Cancer Prev 10: 357-364, 2001

35. Setiawan VW, Yu GP, Lu QY, Lu ML, Yu SZ, Mu L, Zhang JG, Kurtz RC, Cai L, Hsieh CC and Zhang ZF: Allium vegetables and stomach cancer risk in China. Asian Pac J Cancer Prev 6: 387-395, 2005

36. Dorant E, van den Brandt PA, Goldbohm RA and Sturmans F Consumption of onions and a reduced risk of stomach carcinoma. Gastroenterology 110: 12-20, 1996.

37. Muñoz N, Plummer M, Vivas J, Moreno V, De Sanjosé S, Lopez $\mathrm{G}$ and Oliver W: A case-control study of gastric cancer in Venezuela. Int J Cancer 93: 417-423, 2001.
38. You WC, Blot WJ, Chang YS, Ershow A, Yang ZT, An A, Henderson BE, Fraumeni JF Jr and Wang TG: Allium vegetables and reduced risk of stomach cancer. $\mathbf{J}$ Natl Cancer Inst 81: $162-164,1989$.

39. Kim H, Keum N, Giovannucci EL, Fuchs CS and Bao Y: Garlic intake and gastric cancer risk: Results from two large prospective US cohort studies. Int J Cancer 143: 1047-1053, 2018.

40. Gao CM, Takezaki T, Ding JH, Li MS and Tajima K: Protective effect of allium vegetables against both esophageal and stomach cancer: A simultaneous case-referent study of a high-epidemic area in Jiangsu Province, China. Jpn J Cancer Res 90: 614-621, 1999.

41. Pourfarzi F, Whelan A, Kaldor J and Malekzadeh R: The role of diet and other environmental factors in the causation of gastric cancer in Iran-A population based study. Int J Cancer 125: 1953-1960, 2009.

42. Dorant E, van den Brandt PA and Goldbohm RA: A prospective cohort study on the relationship between onion and leek consumption, garlic supplement use and the risk of colorectal carcinoma in The Netherlands. Carcinogenesis 17: 477-484, 1996.

43. Wang W, Dong Z, Zhang X, Li W, Li P and Chen X: Dietary and the risk of sporadic colorectal cancer in China: A case-control study. Iran J Public Health 47: 1327-1335, 2018.

44. Levi F, Pasche C, La Vecchia C, Lucchini F and Franceschi S: Food groups and colorectal cancer risk. Br J Cancer 79: 1283-1287, 1999.

45. Steinmetz KA, Kushi LH, Bostick RM, Folsom AR and Potter JD: Vegetables, fruit, and colon cancer in the Iowa women's health study. Am J Epidemiol 139: 1-15, 1994.

46. Franceschi S, Parpinel M, La Vecchia C, Favero A, Talamini R and Negri E: Role of different types of vegetables and fruit in the prevention of cancer of the colon, rectum, and breast. Epidemiology 9: 338-341, 1998.

47. Yuan P, Lin L, Zheng K, Wang W, Wu S, Huang L, Wu B, Chen T, $\mathrm{Li} X$ and Cai L: Risk factors for gastric cancer and related serological levels in Fujian, China: hospital-based case-control study. BMJ Open 10: e042341, 2020.

48. Galeone C, Pelucchi C,Levi F, Negri E, Franceschi S, Talamini R, Giacosa A and La Vecchia C: Onion and garlic use and human cancer. Am J Clin Nutr 84: 1027-1032, 2006.

49. Witte JS, Longnecker MP, Bird CL, Lee ER, Frank1 HD and Haile RW: Relation of vegetable, fruit, and grain consumption to colorectal adenomatous polyps. Am J Epidemiol 144: 1015-1025, 1996.

50. Annema N, Heyworth JS, McNaughton SA, Iacopetta B and Fritschi L: Fruit and vegetable consumption and the risk of proximal colon, distal colon, and rectal cancers in a case-control study in Western Australia. J Am Diet Assoc 111: 1479-1490, 2011.

51. Myneni AA, Chang SC, Niu R, Liu L, Swanson MK, Li J, Su J, Giovino GA, Yu S, Zhang ZF and Mu L: Raw garlic consumption and lung cancer in a Chinese population. Cancer Epidemiol Biomarkers Prev 25: 624-633, 2016.

52. Shi X, Lv Y, Mao C, Yuan J, Yin Z, Gao X and Zhang Z: Garlic consumption and all-cause mortality among Chinese oldest-old individuals: A population-based cohort study. Nutrients 11: 1504, 2019.

53. Powell JT and Sweeting MJ: Retrospective studies. Eur J Vasc Endovasc Surg 50: 675, 2015

54. Yin X, Zhang R, Feng C, Zhang J, Liu D, Xu K, Wang X, Zhang S, Li Z, Liu X and Ma H: Diallyl disulfide induces G2/M arrest and promotes apoptosis through the p53/p21 and MEK-ERK pathways in human esophageal squamous cell carcinoma. Oncol Rep 32: 1748-1756, 2014.

55. Choi YH: Diallyl trisulfide induces apoptosis and mitotic arrest in AGS human gastric carcinoma cells through reactive oxygen species-mediated activation of AMP-activated protein kinase. Biomed Pharmacother 94: 63-71, 2017.

56. Xiao D, Pinto JT, Gundersen GG and Weinstein IB: Effects of a series of organosulfur compounds on mitotic arrest and induction of apoptosis in colon cancer cells. Mol Cancer Ther 4: 1388-1398, 2005.

57. Shang A, Cao SY, Xu XY, Gan RY, Tang GY, Corke H, Mavumengwana V and Li HB: Bioactive compounds and biological functions of garlic (Allium sativum L.). Foods 8: 246, 2019.

58. Yin X, Zhang J, Li X, Liu D, Feng C, Liang R, Zhuang K, Cai C, Xue X, Jing F, et al: DADS suppresses human esophageal xenograft tumors through RAF/MEK/ERK and mitochondria-dependent pathways. Int J Mol Sci 15: 12422-12441, 2014. 
59. Zhang W, Ha M, Gong Y, Xu Y, Dong N and Yuan Y: Allicin induces apoptosis in gastric cancer cells through activation of both extrinsic and intrinsic pathways. Oncol Rep 24: 1585-1592, 2010.

60. Zhang X, Zhu Y, Duan W, Feng C and He X: Allicin induces apoptosis of the MGC-803 human gastric carcinoma cell line through the p38 mitogen-activated protein kinase/caspase-3 signaling pathway. Mol Med Rep 11: 2755-2760, 2015.

61. Park SY, Cho SJ, Kwon HC, Lee KR, Rhee DK and Pyo S: Caspase-independent cell death by allicin in human epithelial carcinoma cells: Involvement of PKA. Cancer Lett 224: 123-132, 2005.

62. Xiao D, Pinto JT, Soh JW, Deguchi A, Gundersen GG, Palazzo AF, Yoon JT, Shirin H and Weinstein IB: Induction of apoptosis by the garlic-derived compound S-allylmercaptocysteine (SAMC) is associated with microtubule depolymerization and c-Jun $\mathrm{NH}(2)-$ terminal kinase 1 activation. Cancer Res 63: 6825-6837, 2003.

63. Jiang X, Zhu X, Huang W, Xu H, Zhao Z, Li S, Li S, Cai J and Cao J: Garlic-derived organosulfur compound exerts antitumor efficacy via activation of MAPK pathway and modulation of cytokines in SGC-7901 tumor-bearing mice. Int Immunopharmacol 48: $135-145,2017$.

64. Zhu X, Jiang X, Li A, Sun Y, Liu Y, Sun X, Feng X, Li S and Zhao Z: S-allylmercaptocysteine suppresses the growth of human gastric cancer xenografts through induction of apoptosis and regulation of MAPK and PI3K/Akt signaling pathways. Biochem Biophys Res Commun 491: 821-826, 2017.
65. Yan JY, Tian FM, Hu WN, Zhang JH, Cai HF and Li N: Apoptosis of human gastric cancer cells line SGC 7901 induced by garlic-derived compound S-allylmercaptocysteine (SAMC). Eur Rev Med Pharmacol Sci 17: 745-751, 2013.

66. Li X, Ni J, Tang Y, Wang X, Tang H, Li H, Zhang S and Shen X: Allicin inhibits mouse colorectal tumorigenesis through suppressing the activation of STAT3 signaling pathway. Nat Prod Res 33: 2722-2725, 2019.

67. Bat-Chen W, Golan T, Peri I, Ludmer Z and Schwartz B: Allicin purified from fresh garlic cloves induces apoptosis in colon cancer cells via Nrf2. Nutr Cancer 62: 947-957, 2010.

68. Yin X, Feng C, Han L, Ma Y, Jiao Y, Wang J, Jia L, Jing F, Gao X, Zhang Y and Zhang J: Diallyl disulfide inhibits the metastasis of type II esophageal-gastric junction adenocarcinoma cells via NF- $\kappa \mathrm{B}$ and PI3K/AKT signaling pathways in vitro. Oncol Rep 39: 784-794, 2018.

This work is licensed under a Creative Commons Attribution-NonCommercial-NoDerivatives 4.0 International (CC BY-NC-ND 4.0) License. 